\title{
Air, Methylcellulose, Sodium Hyaluronate and the Corneal Endothelium Endothelial Protective Agents
}

\author{
M. G. KERR MUIR, E. S. SHERRARD, V. ANDREWS and A. D. McG. STEELE \\ London.
}

\begin{abstract}
Summary
In a randomised trial the endothelial protective agent used during extracapsular cataract extraction and intraocular lens insertion was air in 19 eyes (group 1), methylcellulose in 25 eyes (group 2) and sodium hyaluronate in 22 (group 3). The cell population densities of each eye were estimated immediately before and three months after the operations to determine the degree of cell loss. Eyes showing mechanical (touch) damage on the second postoperative day were eliminated. The numbers of eyes in each group which showed a statistically significant cell loss were compared, and the mean cell losses in each group were tested for significant differences. It appears that air actually damages the endothelium while methylcellulose and $\mathrm{Na}$-hyaluronate are not harmful, and afford a high, essentially equal degree of endothelial protection.
\end{abstract}

It is common and encouraged practice to maintain, artificially, the anterior chamber (AC) during intraocular anterior segment surgery in order to reduce the risk of damage to the endothelium of the cornea. Originally the lost aqueous humour was replaced with air and/or an irrigation fluid peroperatively. These aqueous substitutes served as spacemakers and held the cornea away from other ocular structures and objects inserted into the AC. They are readily lost through even small incisions and usually require frequent replenishment. Later, viscoelastic solutions proved to be better in that they stay in situ for a considerable time, even if the inculsion is large, and offer some protection to the endothelium because of their slow flow rate and lubricating and cushioning effects. This is of particular importance during the insertion of some intraocular lenses (IOLs) for there appears to be a 'biophysical interaction' between polymethylmethacrylate (PMMA) and the endothelium which results in the stripping away of cell membranes even upon momentary contact. ${ }^{1}$

While there are several viscous substances with the potential to protect the endothelium from mechanical damage, some themselves are noxious to the delicate cells in that they are toxic, of incompatible osmolarity or $\mathrm{pH}$, or prevent the movement of metabolites and waste products. Sodium hyaluronate (NaHA) is the natural shock absorber, structure stabiliser and space separator in the vertebrate body' and occurs naturally in small quantities in the aqueous humour. ${ }^{2}$ It is, therefore, an obvious choice for intraocular use. However, in the concentrations recommended

From Department of Clinical Ophthalmology, Institute of Ophthalmology and Moorfields Eye Hospital, City Road, London.

Correspondence to: A. D. McG. Steele, Moorfields Eye Hospital, City Road, London. EC1V 2PD.

Presented at the Annual Meeting of the Ophthalmological Society of the United Kingdom, April 1987. 
$\mathrm{NaHA}$ is relatively insoluble and only slowly diluted by the aqueous humour before it can pass through the trabeculum. Therefore, if it is not removed from the $\mathrm{AC}$ at the close of surgery it may cause a dangerous rise in intraocular pressure (IOP) $)^{3,4.5 .6 .7 .8}$ or 'Healon-block glaucoma'. ${ }^{9}$ Because of its insolubility and invisibility it is difficult to remove completely. Moreover, it is very expensive. It seems reasonable, therefore, to seek alternatives to NaHA which, while providing its advantages to anterior segment surgery, do not share its drawbacks. Of the other 'tried' viscous substances, hydroxypropylmethylcellulose (HPMC) has been recommended ${ }^{7,10}$ but, largely because it does not occur naturally in animals and is probably not metabolised by humans, its use has been approached with caution in the fear of undesirable ocular or systemic side effects. Rosen et al. ${ }^{11}$ severely criticised its intraocular use on the grounds that most formulations, which are not consistent proprietory products, contain a variety of solid particles-mainly of vegetable matter. Nevertheless, HPMC 2 per cent has been shown in animal models to afford endothelial protection as effectively as $\mathrm{NaHA}$, not itself to affect the morphology or deturgessing activity of the endothelium and to be relatively easy to remove from the AC. ${ }^{12,13}$ Moreover, it has been found to be protective and safe in humans. ${ }^{7,10}$ However, its effect upon the human corneal endothelium has been evaluated only roughly to date.

The aim of this study was to compare the effects of air, HPMC and NaHA themselves upon the human endothelium, as betrayed by cell loss, and upon IOP. Some cell loss is to be anticipated in all anterior segment surgery particularly if a corneal incision is used, but one or other agent used to protect the endothelium against general disturbances may prove less noxious than the others.

\section{Materials and Method \\ Subjects \\ Ninety eyes scheduled for uncomplicated extracap- sular cataract extraction (ECCE) and posterior chamber IOL insertion formed the basis of this study. The protective agent used peroperatively was air in 30 eyes, HPMC in 30 eyes and NaHA in 30 eyes. However, owing to a variety of factors, e.g.}

patient non-attendance for the final examination (15 cases) and pre- and per-operative complications deemed likely to affect the response of the corneal endothelium, e.g. excessive numbers of guttata (1 case), old perforating injury (1 case) and collapse and reformation of the anterior chamber with endothelial touch damage ( 2 cases), or the need to use air in conjunction with a viscous agent ( 5 cases), the study was completed in 66 eyes only. In these air was used in 19 (group 1), HPMC in 25 (group 2) and NaHA in 22 (group 3).

The ages of the subjects ranged from 56 to 86 (mean 71.2) years in group 1, 50 to 85 (mean 72) years in group 2 and 42 to 78 (mean 66.3) years in group 3. Age differences between groups were compared by Analysis of Variance.

At the postoperative evaluations the agent used in each eye was unknown to the examiner.

\section{Surgical Technique}

The operations were performed by three surgeons, but the technique was the same for all eyes. General anaesthesia was used and there was no preoperative ocular decompression. Drops of cyclopentolate 1 per cent phenylephrine 10 per cent were instilled four times during the hour before surgery. There was no superior rectus bridle suture. A seven-eights depth corneal incision of 160 degrees was followed by entry into the $\mathrm{AC}$ with a $27 \mathrm{~g}$ needle. Anterior capsule perforations with a suitably bent $27 \mathrm{~g}$ needle were done without aqueous substitute. The needle entrance was enlarged to $3 \mathrm{~mm}$, aqueous substitute was injected into the AC and the capsule removed with forceps. The corneal incision was completed to full depth, more aqueous substitute injected and the nucleus expressed by two point compression without collapse of the corneal dome. Three 10/0 monofilament nylon sutures were placed in the section and cortical lens matter was aspirated with a McIntyre infusion/aspiration canula. Hartmann's solution was the infusion fluid. Aqueous substitute was injected into the AC prior to the insertion of an Iolab, Cilco or Coburn posterior chamber intraocular lens (IOL). The corneal wound was secured with a total of seven $10 / 0$ monofilament nylon sutures. The aqueous substitute was replaced with Hartmann's solution using the McIntyre canula. Chloramphenicol was instilled into the conjuctival sac at the end of the operation.

\section{Protective Agents}

Hydroxypropylmethylcellulose 2 per cent was prepared in the pharmacy of Moorfields Eye Hospital as follows: A balanced salt solution was made up consisting of 0.075 per cent potassium chloride BP, 0.048 per cent anhydrous calcium chloride, 0.49 per cent sodium chloride $\mathrm{BP}, 0.03$ per cent magnesium 
chloride BP, 0.39 per cent sodium acetate BP, and 0.17 per cent sodium citrate $\mathrm{BP}$ dissolved in water for injections BP to 100 per cent. This solution was filtered through a $0.2 \mu$ absolute filter.

Two g of hydroxypropylmethylcellulose (Methocel E4M Premium) was dissolved in $80 \mathrm{ml}$ of the solution using a silverson mixer. The volume of the resulting solution was made up to $100 \mathrm{ml}$, mixed thoroughly and cooled to about 5 degrees $\mathrm{C}$. This was filtered through a $1.2 \mu$ absolute PTFE filter using a hand syringe and distributed into $5 \mathrm{ml}$. injection vials. The vials were autoclaved at 121 degrees $\mathrm{C}$ for 20 minutes. While cooling, the vials were shaken to obtain a clear solution which was then examined for freedom of particles under magnification and polarised light.

Sodium hyaluronate (Healonid) was used as a 1 per cent solution supplied by Pharmacia Ophthalmics.

\section{Intraocular pressure}

The intraocular pressures of all the eyes were measured by applanation tonometry at routine examinations preoperatively, and postoperatively at one and two days, at intervals during the second and third weeks, at three months, between six and nine months and, where time has allowed, at more than one year.

\section{Specular microscopy. (SM).}

In addition to the routine clinical examinations of each eye, the corneal endothelium was evaluated with the specular microscope (Pocklington, KeelerKonan) on the day before surgery to establish its preoperative condition and to provide the individual 'normal' cell counts, two days after surgery (which is the minimum postoperative time at which SM examination is reasonably tolerated by the patients) to seek acute postoperative changes, e.g. mechanical (touch) damage to the corneal endothelium, and at a minimum time of three months after surgery (when it is considered that the endothelium has recovered and reorganised from any peroperative disturbance ${ }^{14.15 .16}$ ) to determine the cell count in the stabilised endothelium. Cases (2) in which mechanical damage to the endothelium was recognised on the second postoperative day were eliminated from the series because such cell loss would confound the results.

The cell population densities (CPDs) of the individual eyes were estimated from specular photomicrographs taken at the pre- and three month post-operative examinations. During SM scanning of the endothelium, 36 large field specular photomicrographs were taken. These covered the central endothelium within and approximately one $\mathrm{mm}$ outside the innermost posterior corneal ring, ${ }^{17}$ i.e. a total area of about five $\mathrm{mm}$ in diameter, and random peripheral areas including the region of the incision. For each eye, on both occasions, an average of 570 cells was counted and the number of cells $/ \mathrm{mm}^{2}$ estimated in each of a minimum of five pictures of different areas. The mean (which was taken as the CPD) of the estimates, standard deviations (SD) and standard errors of the mean (SEM) were calculated and compared for statistically significant differences (cell loss or gain) between the preoperative and three month postoperative results by the student's t-test. $\mathrm{P}<0.05$ was considered to be statistically significant.

The number of eyes in each group showing a significant endothelial cell loss was determined and tested for intergroup significant differences (chisquared).

The mean preoperative CPDs of each group were compared for statistical differences (student's t-test).

The means of the postoperative CPDs of all the eyes in each group were subtracted from the means of their preoperative CPDs and the difference taken as the absolute cell loss for each group. These were compared for statistically significant differences (student's t-test).

The preoperative CPDs of all the eyes were plotted against their three month CPDs to detect any cases with excessive cell loss, due to touch damage, which had not been recognised by SM on the second postoperative day.

\section{Results}

Age

Testing by Analysis of Variance showed that on the basis of age all three groups could be considered as one.

Preoperatively the endothelia of the subjects in this study showed the usual scatter of age related CPDs. The differences between the mean values of each group $\left(2560\right.$ cells $/ \mathrm{mm}^{2}$ group 1, 2482 cells $/ \mathrm{mm}^{2}$ group 2 and 2622 cells $/ \mathrm{mm}^{2}$ group 3 ) are not significant (Table I). From Table I it can be seen that cell loss is not significantly related to the preoperative CPD.

\section{Intraocular pressure}

Intraocular pressure was within normal range (10 to $22 \mathrm{~mm} \mathrm{Hg}$ ) in all the eyes preoperatively. Three showed an abnormal elevation on the first postoperative day. One of these was $29 \mathrm{~mm} \mathrm{Hg}$ after the use of HPMC and two were 35 and $28 \mathrm{~mm} \mathrm{Hg}$ after the use of 
Table I. Statistical comparisons across groups. $\left(C P D-\right.$ cells $\left./ \mathrm{mm}^{2}\right)$

\begin{tabular}{|c|c|c|c|c|c|c|}
\hline Variable & Group & $n$ & Mean & SEM & $t$ & $P$ \\
\hline $\begin{array}{l}\text { CPD } \\
\text { pre-op }\end{array}$ & $\begin{array}{l}1 \text { (air) } \\
2 \text { (HPMC) } \\
3 \text { (NaHA) }\end{array}$ & $\begin{array}{l}19 \\
25 \\
22\end{array}$ & $\begin{array}{l}2560 \\
2482 \\
2622\end{array}$ & $\begin{array}{r}101 \\
65 \\
56\end{array}$ & 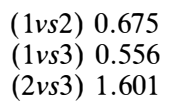 & $\frac{-}{-}$ \\
\hline $\begin{array}{l}\text { CPD } \\
\text { post-op }\end{array}$ & $\begin{array}{l}1 \text { (air) } \\
2 \text { (HPMC) } \\
3 \text { (NaHA) }\end{array}$ & $\begin{array}{l}19 \\
25 \\
22\end{array}$ & $\begin{array}{l}2149 \\
2361 \\
2413\end{array}$ & $\begin{array}{r}109 \\
75 \\
62\end{array}$ & $\begin{array}{ll}(1 v s 2) & 1.651 \\
(1 v s 3) & 2.174 \\
(2 v s 3) & 0.526\end{array}$ & $\overline{<0.05}$ \\
\hline $\begin{array}{l}\text { Cell } \\
\text { loss }\end{array}$ & $\begin{array}{l}1 \text { (air) } \\
2 \text { (HPMC) } \\
3 \text { (NaHA) }\end{array}$ & $\begin{array}{l}19 \\
25 \\
22\end{array}$ & $\begin{array}{l}411 \\
121 \\
209\end{array}$ & $\begin{array}{l}57 \\
29 \\
43\end{array}$ & $\begin{array}{l}(1 v s 2) 4.830 \\
(1 v s 3) 2.886 \\
(2 v s 3) 1.711\end{array}$ & $\begin{array}{c}<0.001) \\
<0.01 \\
-\end{array}$ \\
\hline & $\begin{array}{l}\text { Group } 1 \text { (air) } \\
\text { Group } 2 \text { (HPMC) } \\
\text { Group } 3 \text { (NaHA) }\end{array}$ & - & \multicolumn{4}{|c|}{$\begin{array}{l}\text { Mean per cent cell loss }=16.0 \\
\text { Mean per cent cell loss }=4.9 \\
\text { Mean per cent cell loss }=7.9\end{array}$} \\
\hline
\end{tabular}

Healonid. There was no obvious reason for the rises, and all had returned to normal the next day.

\section{Specular microscopy}

Significant cell losses were evident at three months postoperatively in 18 ( 95 per cent) of the 19 eyes in group 1 , in 12 (48 per cent) of 25 in group 2, and in 13 (59 per cent) of 22 in group 3. (Table II). The difference between groups 2 and 3 is not significant, but group 1 $v s$. groups $2+3$ is significant.

Based upon the mean cell losses of the groups (Table I), the differences between group $1 v s$ group 2, and group $1 v s$ group 3 , are significant. Group $2 v s$ group 3 is not significant.

From the graph, (Fig. 1) it is seen that, except for one eye, the pre- and post-operative CPDs show a straight line relationship.

\section{Discussion}

Intraocular pressure was found to rise and peak at high levels approximately two hours after the intra-AC injection of either HPMC or NaHA in rabbits and monkeys ${ }^{12}$ and in cats $^{13}$ and to return to normal levels within 24 hours. Peak pressures (in the cats) were lower when the protective agent was washed out of the AC after 30 minutes in situ. It is possible, therefore, that elevation of IOP might have been found in more eyes in the present series had tonometry been performed within a few hours of surgery. In the event, only 4.5 per cent of the whole series showed an increase in IOP one day postoperatively and all had resolved by the next day. Since the numbers were so few and occurred after the use of HPMC and NaHA, it seems probable that the increase in IOP was due to factors other than the protective agents.

On averaging the percentages of endothelial cells lost during IOL implantation published by a number of surgeons, Bourne et al. ${ }^{18}$ noted that 16 per cent of the cells were lost

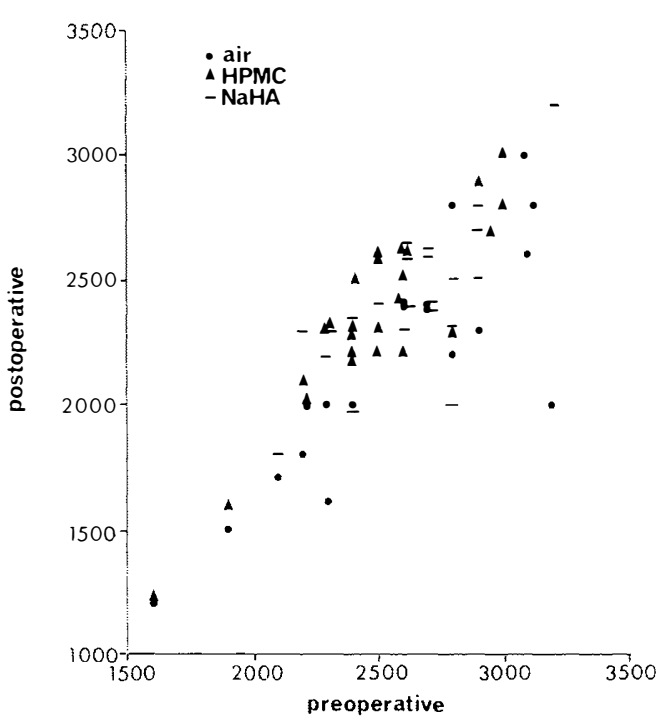

Fig. 1. Preoperative endothelial CPDs (cells $\left./ \mathrm{mm}^{2}\right)$ of all the eyes plotted against their 3 month postoperative CPDs. 
Table II. Comparison of number of eyes/group with significant cell loss, at three months postoperatively. Chi-squared test

\begin{tabular}{lccc}
\hline Group & $\begin{array}{c}\text { No. eyes } \\
\text { with cell loss }\end{array}$ & $\begin{array}{c}\text { No. eyes } \\
\text { with no loss }\end{array}$ & $\begin{array}{c}\text { per cent } \\
\text { cell loss }\end{array}$ \\
\hline 1 (air) & 18 & 1 & 95 \\
2 (HPMC) & 12 & 13 & 48 \\
3 (NaHA) & 13 & 9 & 59 \\
\hline
\end{tabular}

Overall chi-squared $=10,920$ for $2 \mathrm{df} P<0.01$.

Groups 2 and 3 do not differ.

Group 1 vs $2+3$ yields chi-squared $=10,286$ for $1 \mathrm{df}$ $\mathrm{P}<0.01$.

when air was used in the anterior chamber compared to 37 per cent when it was not. They performed a prospective study and found a statistically significant difference of 15 per cent loss with air against a 32 per cent loss without it. They concluded that the use of air in the AC can help to prevent endothelial cell loss by serving as a space-maker and so reduce the incidence of IOL/endothelium contact. They stated that air did not seem to harm the endothelium.

Eiferman and Wilkins ${ }^{19}$ reported a statistically significant difference in the loss of human cells, 18.5 per cent $v s 8.5$ per cent, after prolonged exposure of the endothelium to an air bubble vs balanced salt solution (BSS) respectively, in the ACs of patients undergoing cataract extraction. However, the time of exposure far exceeded the peroperative period. Aran-Rosa et $a l^{10}$ found a significant difference of cell loss between groups of patients in whom IOLs were implanted with the use of air, 25.3 per cent cell loss, and with methylcellulose, 8 per cent loss. Alpar ${ }^{20}$ reported significant differences of endothelial cell loss between patients having intracapsular cataract extraction with IOL implantation and keratoplasty with BSS/air, 24.4 per cent cell loss, or Healon, 14.3 per cent loss, in the AC.

Leibowitz and Laing ${ }^{21}$ had shown that air in the AC induced specular microscopically visible morphological changes of scattered endothelial cells in in vitro rabbit eyes. The nature of the changes has never been directly elucidated but, from comparative observations it seems probable that most are intracellular vacuoles and that only a proportion of the affected cells survive. ${ }^{22}$
In that it has no cushioning or lubricating effects, air affords no endothelial protection, and it might be that the large loss of endothelial cells which resulted in the various studies after its use compared to that after the use of HPMC or NaHA is a result of 'touch' damage. However, the straight line relationship of cell loss in the present study indicates that all cases, except one, in which mechanical damage had occurred were successfully recognised and rejected from the series on the second postoperative day. It seems probable, therefore, that some cells are lost as a result of air interfacing with the endothelium peroperatively.

Both HPMC and NaHA have been shown to protect the endothelium from touch damage in in vitro and in vivo animal ${ }^{12,23,24,25,26}$ and human ${ }^{4,7.10,20,27,28}$ studies. Neither agent has been shown to be noxious. No immediate ill effects upon the endothelial pump/leak relationship were found in perfusion experiments, ${ }^{12}$ although some delayed, short lived, small increases in corneal thickness, indicating temporary embarassment of the endothelium, have been reported to occur in vitro ${ }^{12}$ and in $v i v o^{13}$ in animals with HPMC and NaHA. The present clinical study finds no statistically significant difference between the degree of cell loss, which can be attributed to a noxious effect, following HPMC or NaHA. It is noteworthy, however, that HPMC appears to be followed by a marginally lower cell loss than NaHA.

Hammer and Thomas ${ }^{26}$ demonstrated that HPMC and NaHA are pseudoplastic fluids, i.e. their viscosities decrease with increasing shear rate. They showed that, at the concentrations used in the present study-2 per cent HPMC and 1 per cent $\mathrm{NaHA}$ - which give high viscosities at rest and so serve admirably as space makers, the viscosity of a thin layer of NaHA remains high enough at moderate shear rataes to transmit the shear forces to the endothelium. They found the endothelial 'protective' effect of a thin layer of $\mathrm{NaHA}$ was equivalent to that of BSS; over 40 per cent of the cells of a test cornea were damaged.

It would appear, then, that a variety of investigations find that as spacemakers and endothelial protective agents, HPMC and 
NaHA are good and equivalent providing that the distance between the posterior corneal surface and an object in the AC is kept large enough in the presence of 1 per cent NaHA to disallow the transmission of shear forces to the endothelium. Neither agent, in contrast to air, is noxious to the endothelium; most of the cell loss and changes of morphology being the result of peroperative ocular insult beyond the protective scope of the agents.

\section{FOOTNOTE:}

Since the completion of this study the method of preparation of the HPMC has been modified in a number of ways and both the final product and the raw material powder, are routinely examined microscopically to ensure an almost complete absence of plant material.

We are greatly indebted to Dr. William $\mathrm{Ng}$ for all the cell counting and provision of the preliminary statistical data, and to Professor S. E. Smith and Dr. I. Grierson who willingly performed the statistical analyses.

\section{References}

${ }^{1}$ Katz J, Kaufman HE, Goldberg EP, Sheets JW: Prevention of endothelial damage from intraocular lens insertion. Trans Am Acad Ophthalmol and Otolaryngol 1977, 83: 204-12.

${ }^{2}$ Balazs EA: Sodium Hyaluronate and Viscosurgery. In Miller D, \& Stegman R eds.: Healon-a guide to its use in ophthalmic surgery. John Wiley \& Sons. New York. 1983 5-28.

${ }^{3}$ Binkhorst CD: Inflammation and intraocular pressure after the use of Healon in intraocular lens surgery. Am Intraocular Implant Soc J 1980, 6: $340-1$.

${ }^{4}$ Pape LG: Intracapsular and extracapsular techniques of lens implantation with Healon. Am Intraocular Implant Soc J 1980, 6: 342-3.

${ }^{5}$ Percival SPB: Complications from use of sodium hyaluronate (Healonid) in anterior segment surgery. Br J Ophthalmol 1982, 66: 714-6.

${ }^{6}$ Cherfan GM, Rich WJ, Wright G: Raised intraocular pressure and other problems with sodium hyaluronate and cataract surgery. Trans Ophthalmol Soc UK 1983, 103: 227-32.

${ }^{7}$ Fechner PU and Fechner MU: Methylcellulose and lens implantation. $\mathrm{Br} J$ Ophthalmol 1983, 67: 259-63.

${ }^{8}$ Barron BA, Busin M, Page C, et al.: Comparison of the effects of Viscoat and Healon on postoperative intraocular pressure. AmJ Ophthalmol 1985, 100: 377-84.

${ }^{9}$ Hoffer JK: Effects of extracapsular implant techniques on endothelial cell density. Arch Ophthalmol 1982, 100: 791-2.

${ }^{10}$ Aron-Rosa D, Cohn HC, Aron J-J, Bouquety C: Methylcellulose instead of Healon in extracapsu- lar surgery with intraocular lens implantation. Am Acad Ophthalmol 1983, 90: 1235-8.

${ }^{11}$ Rosen ES, Gregory PF, Barnett F: Is 2 per cent hydroxypropylmethylcellulose a safe solution for intraoperative clinical application? J Cataract Refract Surg 1986, 12: 679-84.

${ }^{12}$ MacRae SM, Edelhauser HF, Hyndiuk RA, et al.: The effects of sodium hyaluronate, chondroitin sulphate and methylcellulose on the corneal endothelium and intraocular pressure. $\mathrm{Am} \mathrm{J}$ Ophthalmol 1983, 95: 332-41.

${ }^{13}$ Glasser BD, Matsuda M, Edelhauser HF: A comparison of the efficacy and toxicity of and intraocular pressure response to viscous solutions in the anterior chamber. Arch Ophthalmol 1986, 104: 1819-24.

${ }^{14}$ Matsuda M, Sawa M, Edelhauser HF, et al.: Cellular migration and morphology in corneal endothelial wound repair. Invest Ophthalmol Vis Sci 1985, 26: 443-9.

${ }^{15}$ Yee R, GeroskiD, Matsuda M, et al.: Correlation of corneal endothelial pump site density, barrier function and morphology in wound repair. Invest Ophthalmol Vis Sci 1985, 26: 1191-201.

${ }^{16}$ Schultz RO, Glasser DB, Matsuda M. et al.: Response of the corneal endothelium to cataract surgery. Arch Ophthalmol 1986, 104: 1164-9.

${ }^{17}$ Sherrard ES and Buckley RJ: Endothelial wrinkling-a complication of clinical specular microscopy. In Trevor-Roper P. ed. The cornea in health and disease VI Cong Euro Soc Ophthalmol Academic Press Inc London. 1980 69-74.

${ }^{18}$ Bourne WM, Brubaker RF, O'Fallo WM: Use of air to decrease endothelial cell loss during intraocular lens implantation. Arch Ophthalmol 1979, 97: 1473-5.

${ }^{19}$ Eiferman RA and Wilkins EL: The effect of air on human corneal endothelium. Am J Ophthalmol 1981, 92: 328-31.

${ }^{20}$ Alpar JJ: The use of Healon in corneal transplant surgery with and without intraocular lenses. Ophthalmic Surg 1984, 15: 757-60.

${ }^{21}$ Leibowitz HM and Laing RA: Corneal endothelium: The effect of air in the anterior chamber. Arch Ophthalmol 1974, 92: 227-30.

${ }^{22}$ Sherrard ES: The corneal endothelium in vivo: its - response to mild trauma. Exp Eye Res 1976, 3: 47-57.

${ }^{23}$ Graue EL, Polack FM, Balasz EA: The protective effect of $\mathrm{Na}$-hyaluronate to corneal endothelium. Exp Eye Res 1980, 31: 119-27.

${ }^{24}$ Bahn CF, Grosserode R, MacCallum DK, et al.: Effect of Healon on feline corneal endothelium. Invest Ophthalmol Vis Sci 1983 Suppl 24175.

${ }^{25}$ Miyauchi S and Iwata S: Biochemical studies on the use of sodium hyaluronate in the anterior eye segment: IV the protective efficacy of the corneal endothelium. Curr Eye Res 1984, 3: 1063-7.

${ }^{26} \mathrm{Hammer} \mathrm{ME}$ and Burch TG: Viscous corneal protection by sodium hyaluronate, chondroitin sulphate, and methylcellulose. Invest Ophthalmol Vis Sci 1984, 25: 1329-32. 
${ }^{27}$ Miller D and Stegman R: Use of sodium hyaluronate in human IOL implantation. Ann Ophthalmol 1981, 13: 811-5.

2x Stegmann R and Miller D. Extracapsular cataract extraction with Healon using a corneal incision. In Miller D and Stegman R eds.: Healon-a guide to its use in ophthalmic surgery. John Wiley \& Sons New York 1983 45-47. 